\title{
A comparative study between NSMC and NSOSMC strategy for a DFIG integrated into wind energy system
}

\author{
Habib Benbouhenni \\ National Polytechnique School of Oran \\ Maurice Audin, Oran, Algeria \\ habib0264@gmail.com
}

\begin{abstract}
This article presents a modelling and sliding mode control (SMC) of a doubly fed induction generator (DFIG) integrated into wind energy system for independent control of stator reactive and stator active powers. For a comparative study, the independent control of reactive and active powers is ensured in the first step by neuro-sliding mode controllers (NSMC) and the second step by neuro-second order sliding mode controllers (NSOSMC). Finally, the performance of the system is tested and compared by simulation in terms of robustness tests, and reference tracking tests based on Matlab/Simulink software.
\end{abstract}

Keywords- Doubly fed induction generator, sliding mode control, neuro-sliding mode controllers, neuro-second order sliding mode controllers, wind energy system

\section{INTRODUCTION}

The conventional control strategy of a doubly fed induction generator is the vector control (VC), where the stator reactive power and stator active power are controlled using current regulator blocks [1]. In the VC control strategy, the decoupling between q-axis and d-axis current is achieved with feedforward compensation. On the other hand, this control technique is strongly dependent on machine parameters, uses multiple loops, and requires much regulation effort to guaranteed structure stability over the total velocity rang [2]. In the conventional VC control, stator reactive power and stator active power can be directly controlled by using proportional-integral (PI) regulators. Nevertheless, a few disadvantages limit the use of the PI controllers, such as electromagnetic torque ripple, stator active power ripple and stator reactive power ripple.

Since the SMC method has been widely used for nonlinear systems and robust control scheme. This technique proposed by Utkin in 1977 [3]. However, robustness is the best advantage of an SMC control scheme. The principal disadvantage of the SMC strategy is the chattering phenomenon caused by the discontinuous control strategy [4]. In order to overcome the drawbacks of the SMC technique, second order sliding mode control has been presented [5-7]. This strategy based on the super twisting algorithm (ST) proposed by Levant [8]. On the other hand, this strategy is a simple control scheme and easy to implement compared to other control techniques. In addition, this strategy gives a minimum total harmonic distortion (THD) of stator current and electromagnetic torque compared to the SMC control scheme. Some useful solutions for sliding mode VC control with less stator reactive power and stator active power ripples used in DFIG-based wind turbines were described in [9-11]. In [12], the authors proposed the use of a VC strategy with SOSMC regulators to regulator stator active power and reactive power. Fuzzy logic (FL) and SMC strategy are combined to control the DFIG-based wind energy conversion system [13]. Neuro-sliding mode regulator is proposed to control the active and reactive powers of the DFIG [14]. SOSMC control and FL controllers are combined to regulate the DFIG [15]. Neuro-second order sliding mode control is proposed to control a doubly fed induction generator [16]. In this paper, Coordinated vector control of the RSC and GSC (grid side converter) is presented. The grid side converter is controlled based on the VC principle to control the DC-link voltage, total reactive and active stator power. The RSC is controlled to control the reactive and active stator powers. To obtain high- performance VC control, two different control schemes will be compared with each other. These two control strategies are neuro-second order sliding mode control and neuro-sliding mode control scheme. The proposed scheme preserves the advantages of classical VC control scheme such as simplicity, fewer parameters dependence and fast response. The stability of the NSMC strategy and NSOSMC controller is proven using Lyapunov stability theorem. Finally, the proposed control schemes performance is verified by the simulation study on 1.5 MW DFIG-based WECSs under reference tracking, harmonic distortion of stator current and machine parameters.

\section{NSVM TECHNIQUE}

Traditionally the pulse width modulation (PWM) strategy is widely used in AC machine drive. This strategy is a simple scheme and easy to implement compared to classical space vector modulation (SVM). However, this technique has the following drawbacks. This strategy gives more THD value of stator current. This technique gives more electromagnetic torque ripple, stator active power ripple and reactive power ripple compared to SVM strategy. In order to overcome the drawbacks of the PWM technique, intelligent SVM technique has been presented $[17,18]$. FL controller and SVM technique are combined to control the RSC converter of DFIG [19]. In 
[20], a three-level neural space vector modulation (NSVM) technique was designed to determine directly the switching state of RSC for the DFIG. An FPWM was designed to control a doubly fed induction generator [21]. this strategy reduces the THD value of stator current, electromagnetic torque ripple, stator reactive power ripple and active power ripple compared to classical SVM strategy.

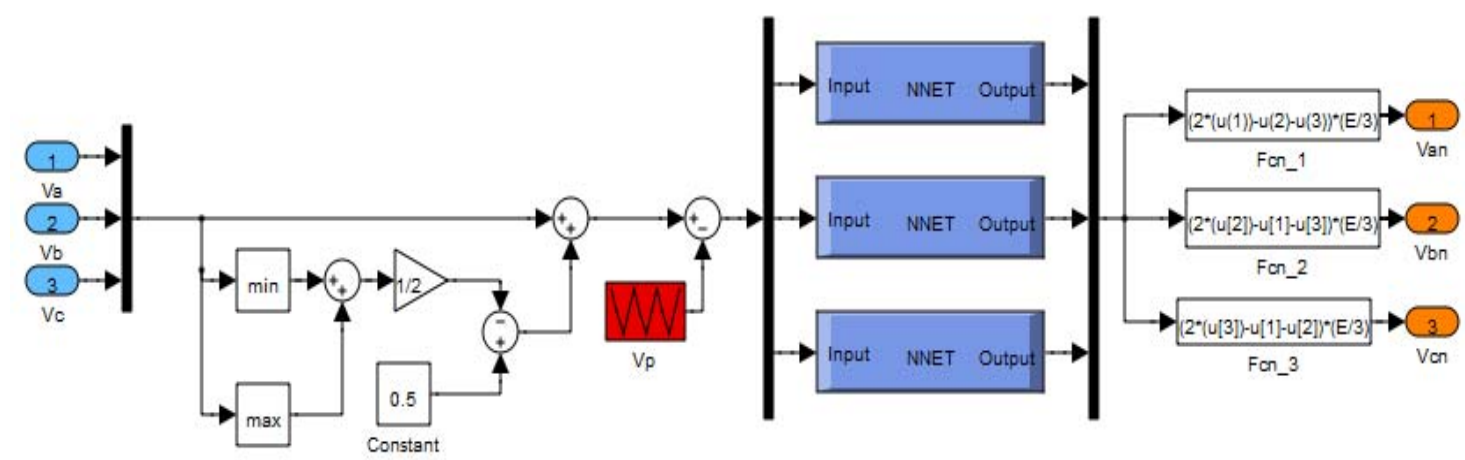

Fig. 1 NSVM technique block.

The principle of the two-level NSVM technique is similar to the classical SVM strategy. However, the hysteresis comparators are replaced by artificial neural network (ANN) controllers. This technique is simple and easy to implement.

The structure of the ANN controller used to perform the SVM technique is an ANN with one linear input node, 12 neurons in the hidden layer, and one neuron in the output layer. The convergence of the network in summer obtained by using the value of the parameters grouped in Table 1.

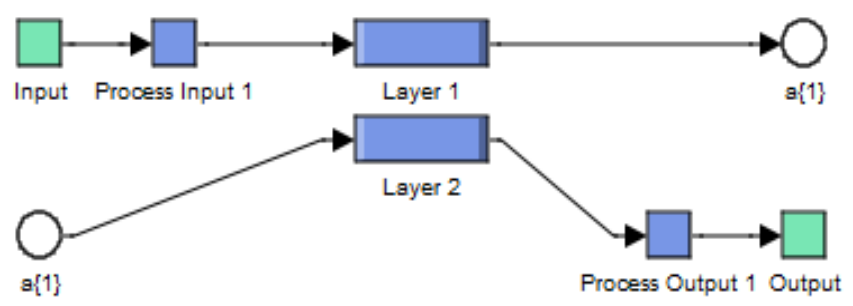

Fig. 2 ANN hysteresis comparators block.
TABLE 1. PARAMETERS OF THE LM FOR HYSTERESIS CONTROLLERS

\begin{tabular}{|l|c|}
\hline \multicolumn{1}{|c|}{ Parameters of the LM } & Values \\
\hline Number of hidden layer & 12 \\
\hline TrainParam.Lr & 0.002 \\
\hline TrainParam.show & 50 \\
\hline TrainParam.eposh & 1000 \\
\hline Coeff of acceleration of convergence $(\mathrm{mc})$ & 0.9 \\
\hline TrainParam.goal & 0 \\
\hline TrainParam.mu & 0.9 \\
\hline Functions of activation & Tensing, Purling, gensim \\
\hline
\end{tabular}

\section{CONTROL TECHNIQUES OF THE DFIG}

In this part, comparison of doubly fed induction generator using different control strategies: neuro-sliding mode controller and neuro-second order sliding mode controller.

\subsection{Neuro-sliding mode controller}

The sliding mode reactive and active stator powers controllers are designed to respectively change the $d$ and $q$ axis voltages $\left(V_{q r}^{*}\right.$ and $\left.V_{d r}^{*}\right)$ as in Eqs. (1).

$$
\left\{\begin{array}{l}
V_{d r}^{e q}=R_{r} \cdot I_{d r}-L_{s} \frac{\left(L_{r}-\frac{M^{2}}{M L_{s}}\right)}{M \psi_{s} w_{s}} \dot{Q}_{s r e f}-g \cdot w_{s} \cdot\left(L_{r}-\frac{M^{2}}{L_{s}}\right) \cdot I_{q r}+\frac{\left(L_{r}-\frac{M^{2}}{L_{s}}\right)}{M} w_{s} \\
V_{q r}^{e q}=R_{r} \cdot I_{q r}+\frac{L_{s}}{V_{s} M \dot{P}_{s_{r e f}}-g \cdot w_{s} \cdot\left(L_{r}-\frac{M^{2}}{L_{s}}\right) \cdot I_{d r}+g \cdot \frac{M \cdot V_{s}}{L_{s}}}
\end{array}\right.
$$

To obtain good performances, dynamic and a commutation around the surface, the control vector is imposed as follows:

$V_{d q}=V_{d q}^{e q}+V_{d q}^{n}$

$V_{d q}^{n}$ is the saturation function defined by :

The block diagram of the two-level NSVM technique applied to the DFIG is illustrated in Fig. 1. On the other hand,

$$
V_{d q}^{n}=-K \cdot \operatorname{sat}\left(S_{d q}\right)
$$

Where $K$ determine the ability of overcoming the chattering.

The SM will exist only if the following condition is met:

$$
S . \dot{S} \prec 0
$$

The disadvantage of SMC control scheme is the harmonic distortion of current, chattering effect and powers ripples. In 
order to reduce the harmonic distortion, powers ripples and chattering phenomenon, a neuro-sliding mode control has been proposed.

The NSMC control scheme is a modification of the SMC technique, where the switching controller term sat $(\mathrm{S}(\mathrm{x}))$, has been replaced by a neural networks control input as given below [22].
$V_{d q}^{c o m}=V_{d q}^{e q}+V_{d q}^{\text {Neural }}$

The proposed NSMC control scheme, which is designed to control the stator reactive and stator active powers of the doubly fed induction generator is shown in Fig. 3.

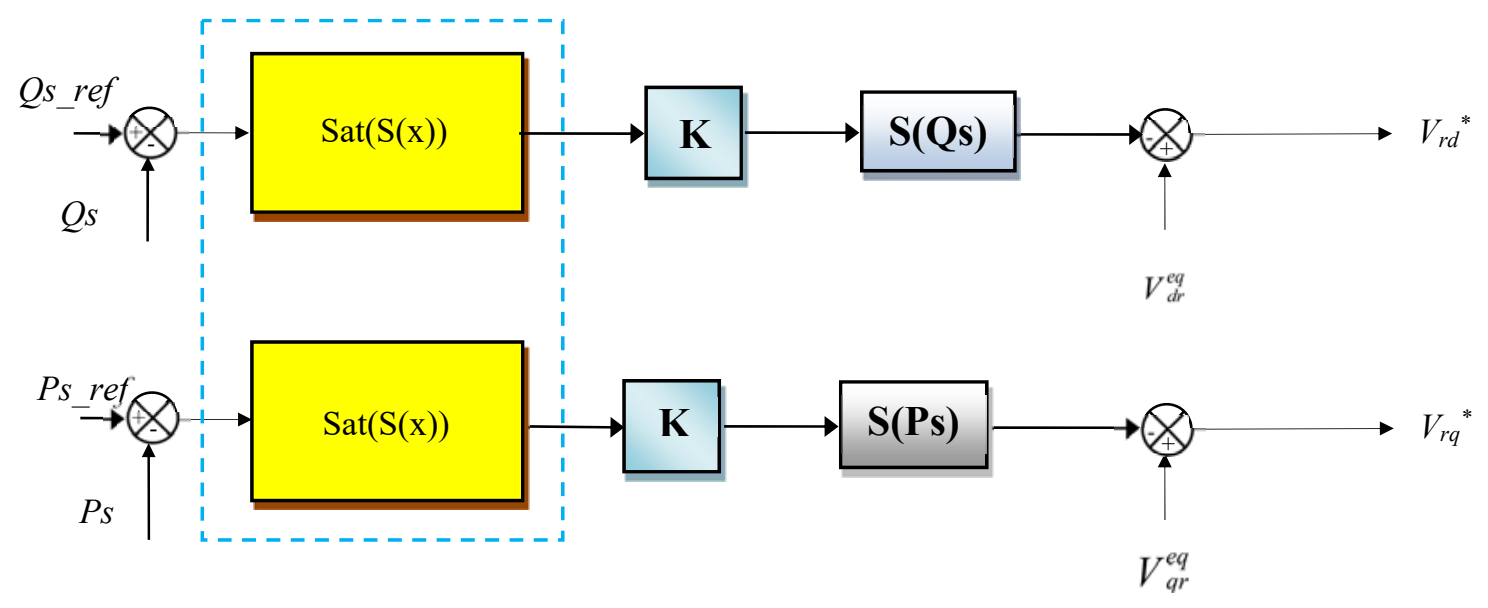

a)SMC

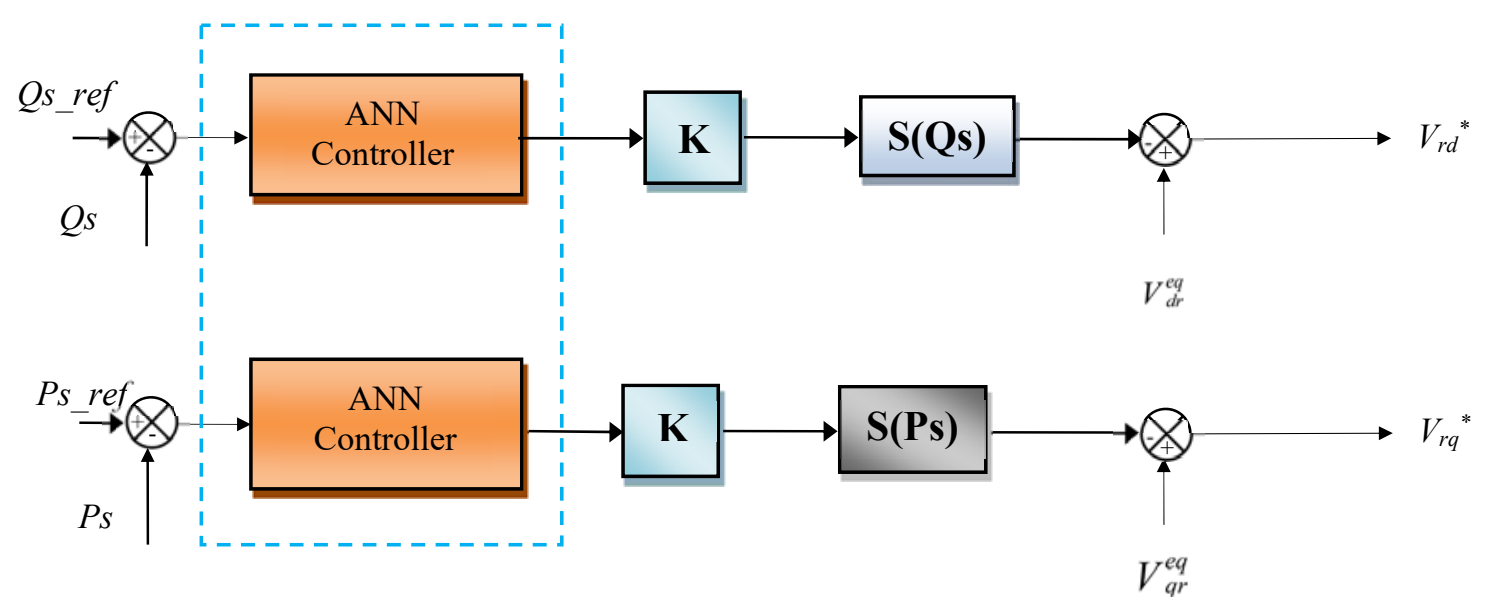

b) NSMC

Fig. 3 Block diagram of the power control of the DFIG.

For the two proposed neuro-sliding mode controllers in Fig. 4, the structure of the NN with one linear input node, 8 neurons in the hidden layer and one neuron in the output layer.

The training used is that of the algorithm, Gradiant descent with momentum \& Adaptive LR. The number of the iteration count maximum 1000 with an iteration step of 50 .

Fig. 5 represents the SMC control of DFIG driven by a two-level NSVM strategy.

\subsection{Neuro-second order sliding mode control}

The NSOSMC goal is to control the active and reactive stator powers of the doubly fed induction generator. In the NSOSMC, reactive stator power is controlled by means of

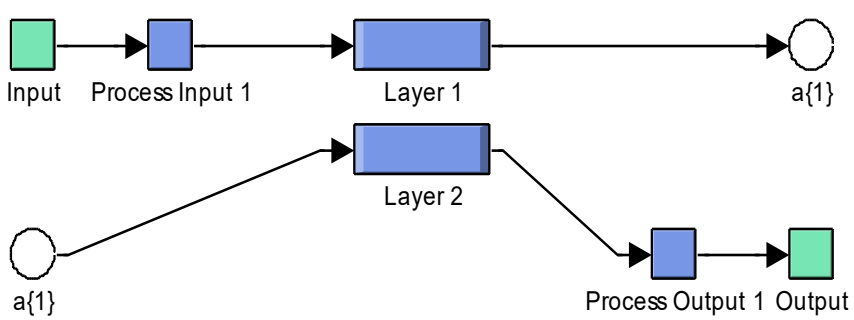

Fig. $4 \mathrm{ANN}$ controller block for reactive and active powers.

the direct axis voltage $\mathrm{V}_{\mathrm{dr}}$, while the active stator power is controlled by means of the quadrature axis voltage $\mathrm{V}_{q r}$.

The proposed NSOSMC-NSVM control, which is designed to control stator active power and stator reactive power of the doubly fed induction generator, is shown in Fig. 6. 


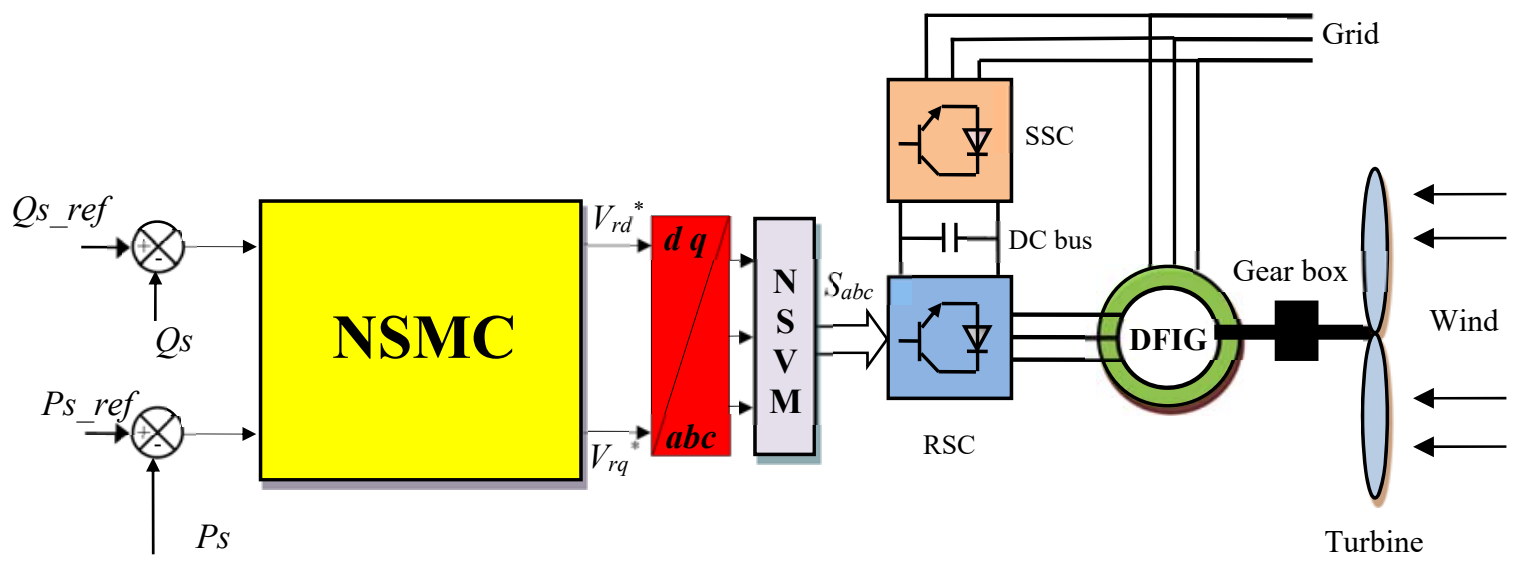

Fig. 5 NSMC-NSVM diagram.

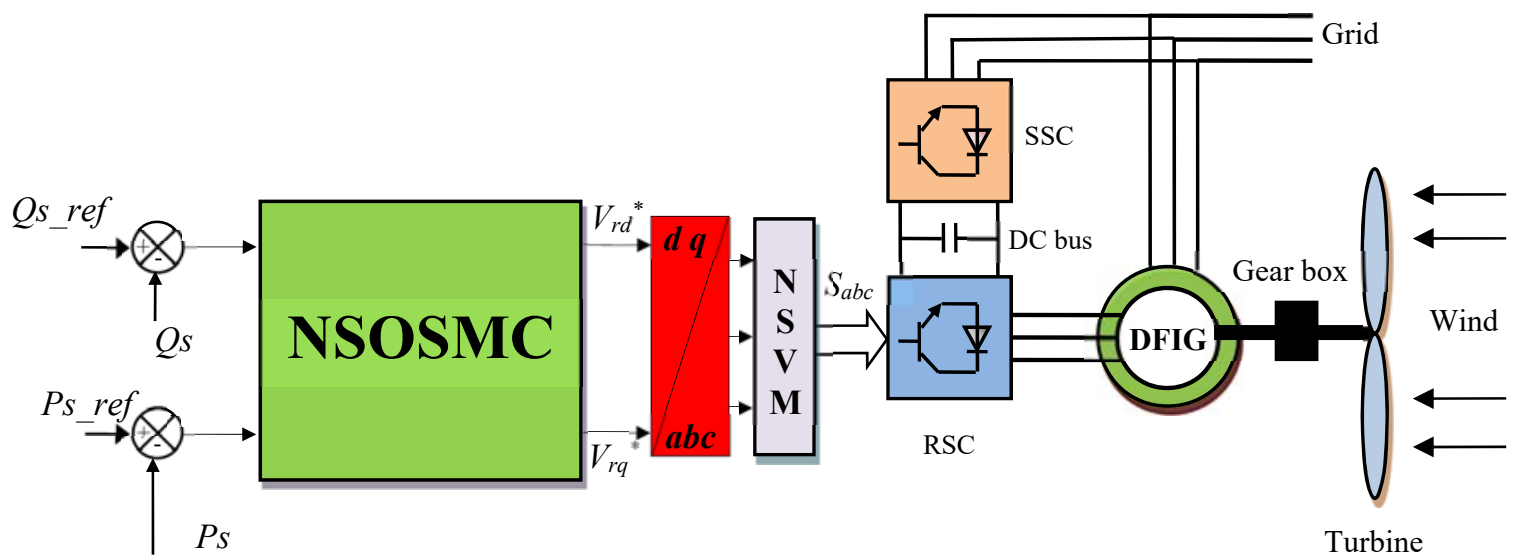

Fig. 6 NSOSMC-NSVM diagram.

The SOSM stator active and stator reactive powers controllers are designed to respectively change the $d$ and $q$ axis voltages $\left(V_{q r}^{*}\right.$ and $\left.V_{d r}^{*}\right)$ as in Eqs. (6) and (8) [16].

$V_{d r}=u_{1}+u_{2}$

With:

$$
\left[\begin{array}{l}
u 1 \\
u_{2}
\end{array}\right]=\left[\begin{array}{c}
-\lambda_{1} \operatorname{sign}\left(S_{q}\right) \\
-\delta_{1}\left|S_{q}\right|^{0.5} \operatorname{sign}\left(S_{q}\right)
\end{array}\right]
$$

$V_{q r}=w_{1}+w 2$

With:

$$
\left[\begin{array}{l}
w 1 \\
w 2
\end{array}\right]=\left[\begin{array}{c}
-\lambda_{2} \operatorname{sign}\left(S_{p}\right) \\
-\delta_{2}\left|S_{p}\right|^{0.5} \operatorname{sign}\left(S_{p}\right)
\end{array}\right]
$$

Here, the stator reactive power magnitude error $S_{q}=Q s_{\text {ref }}-$ $Q s$ and the stator active power error $S_{p}=P s_{\text {ref }}-P s$ are the sliding variables, and the constant gains $\lambda_{1}, \lambda_{2}, \delta_{1}$ and $\delta_{2}$ must check the stability conditions.

To ensure the convergence of regulators in the infinity of time constants and are chosen to satisfy the following inequality:

$$
\left\{\begin{array}{c}
\lambda_{i} \leq \frac{\mu_{i}}{\sigma \cdot L_{r}} \\
\delta_{i} \geq \frac{4 \mu_{i}\left(\lambda_{i}+\mu_{i}\right)}{\left(\lambda_{i}-\mu_{i}\right)\left(L_{r} \sigma\right)^{2}} \\
\left|A_{i}\right| \prec \mu_{i} ; i=1,2
\end{array}\right.
$$

Fig. 7 shows the block diagram of SOSMC control scheme.

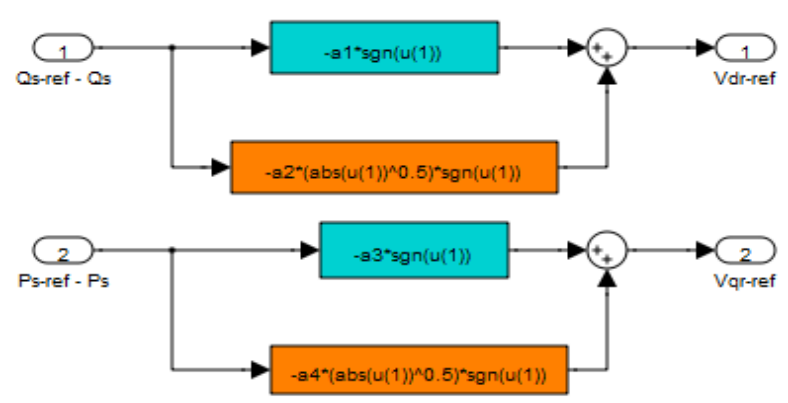

Fig. 7 Block diagram of SOSMC method.

The disadvantage of SOSMC control of the DFIG is that the electromagnetic torque ripple, stator reactive power ripple, harmonic distortion of rotor current and active power ripple. 
In order to eliminate the ripple in torque, reactive and stator active power, we propose to use the neuro-sliding mode control (NSOSMC). Artificial Neural Networks (ANNs) have been used in many areas. ANN controller was first introduced by Warren McCulloch and Walter Pitts. ANN control does not need a mathematical model of the system. However, the ANN controller contains three layers: input layers, hidden layers and output layers. Each layer is composed of several neurons [23].

One way to improve SOSMC control performance is to combine it with the ANN controller to form NSOSMC control. The design of a SOSMC control incorporating neural control helps in achieving reduced reactive stator power ripple, electromagnetic torque ripple, THD value of rotor current and chattering phenomenon. On the other hand, NSOSMC control is a simple control scheme and easy to implement compared to the conventional control scheme.

The NSOSMC controller is a modification of the SOSMC controller, where the switching controller term $\operatorname{sgn}(\mathrm{S}(\mathrm{x}))$, has been replaced by a neural control as shown in Fig. 8 .
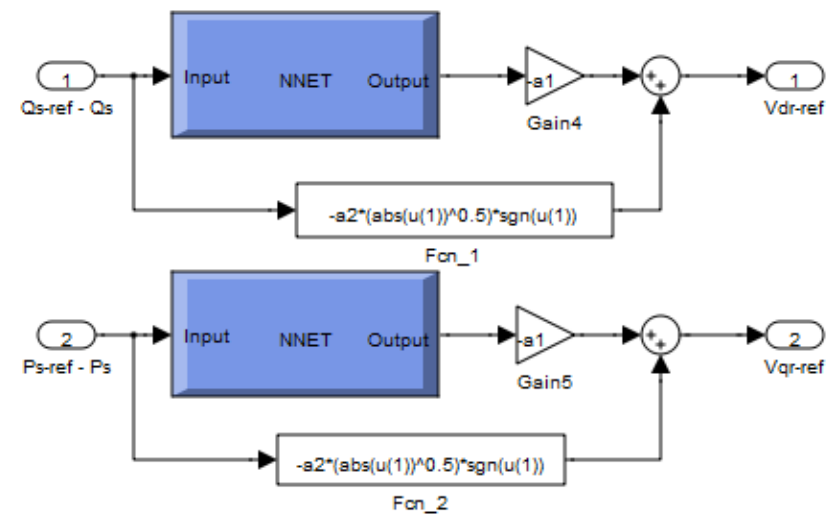

Fig. 8 NSOSMC control block.

Fig. 9 shows the neural network training performance of ANN controllers for active stator and reactive stator powers.

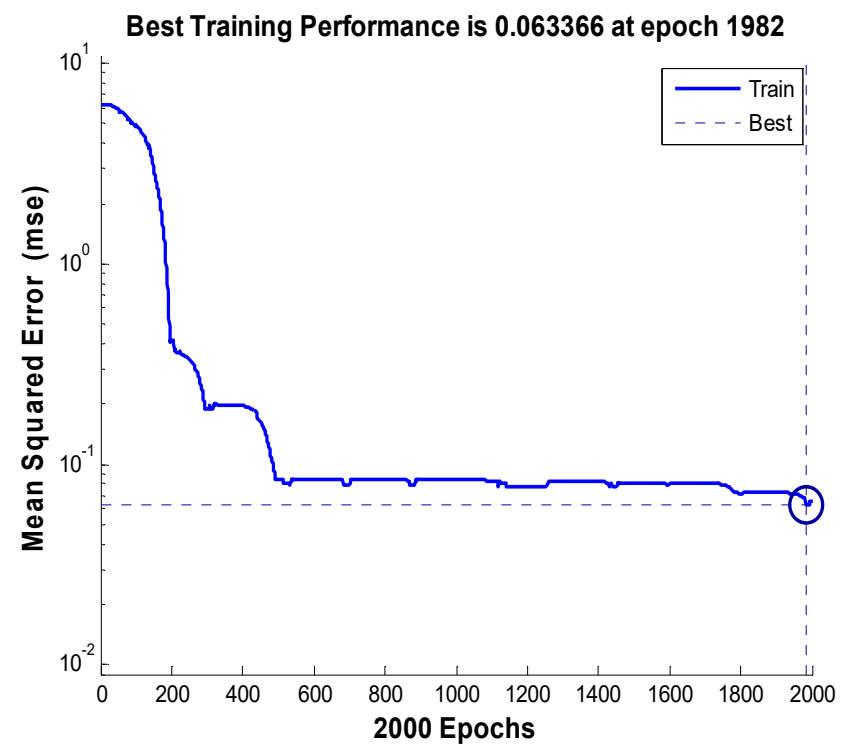

Fig. 9 Neural network training performance.

\section{SimUlATION RESUlTS}

In this part, simulation is realized with a $1.5 \mathrm{MW}$ DFIG coupled to a $398 \mathrm{~V} / 50 \mathrm{~Hz}$ grid. The simulation results of NSOSMC-NSVM control are compared with the NSMCNSVM control scheme. For this end, the controls system was tested under deferent operating conditions such as reference tracking test. The performance analysis is done with a THD value of stator current, reactive power, electromagnetic torque, stator current and active power.

The DFIG used in this case study is a $1.5 \mathrm{MW}, 380 / 696 \mathrm{~V}$, two poles, $50 \mathrm{~Hz}$; with the following parameters: $\mathrm{Rs}=$ $0.012 \Omega, \mathrm{Rr}=0.021 \Omega, \mathrm{Ls}=0.0137 \mathrm{H}, \mathrm{Lr}=0.0136 \mathrm{H}$ and $\mathrm{Lm}$ $=0.0135 \mathrm{H}, \mathrm{J}=1000 \mathrm{~kg} \cdot \mathrm{m} 2, \mathrm{fr}=0.0024 \mathrm{Nm} / \mathrm{s}$.

\section{A. Reference tracking test (RTT)}

From the simulation results presented in Figs. 10-11 it is apparent that the THD value of stator current for the NSOSMC-NSVM control is considerably reduced. Table 2 shows the comparative analysis of THD value for stator current.

TABLE 2. COMPARATIVE ANALYSIS OF THD VALUE

\begin{tabular}{|c|c|}
\hline NSMC-NSVM & NSOSMC-NSVM \\
\hline $0.26 \%$ & $\mathbf{0 . 2 1} \%$ \\
\hline
\end{tabular}

Figs 12-14 show the obtained simulation results. As it's shown in Figs 13-14, for the NSOSMC-NSVM control and NSMC-NSVM control scheme, the stator active power (Ps) and stator reactive power (Qs) tracks almost perfectly their references values $\left(\mathrm{Ps}_{\text {ref }}\right.$ and $\left.\mathrm{Qs}_{\text {ref }}\right)$. Moreover, the NSOSMC control scheme using the two-level NSVM technique minimized the electromagnetic ripple, stator current ripple, stator active power ripple and reactive power ripple compared to the NSMC control using NSVM technique (See Figs 1517).
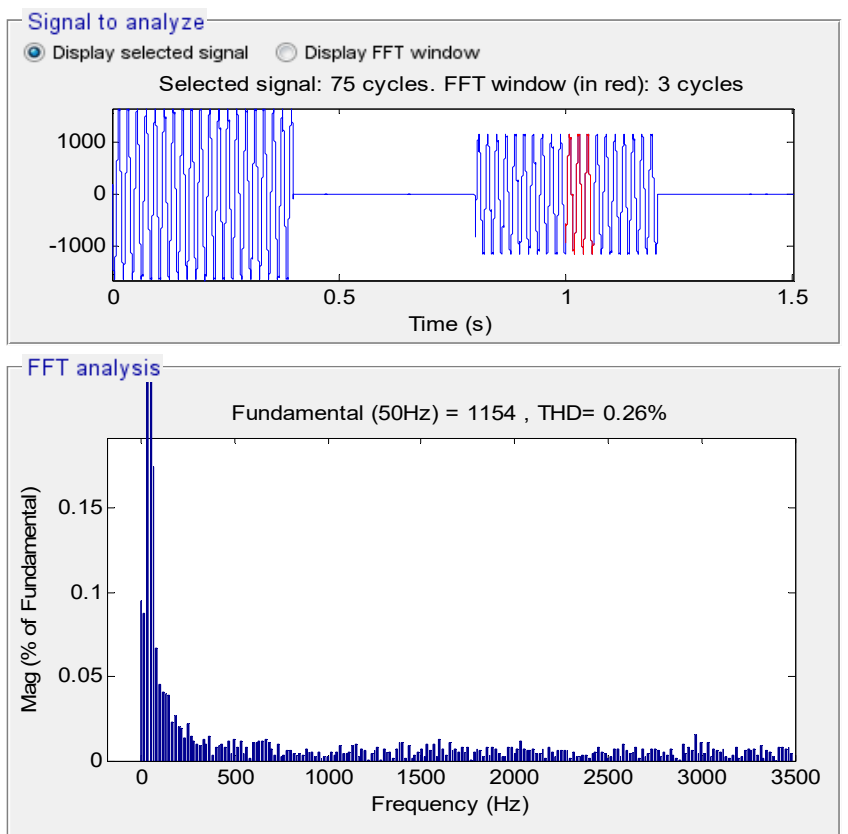

Fig. 10 Spectrum harmonic of stator current (NSMC-NSVM). 

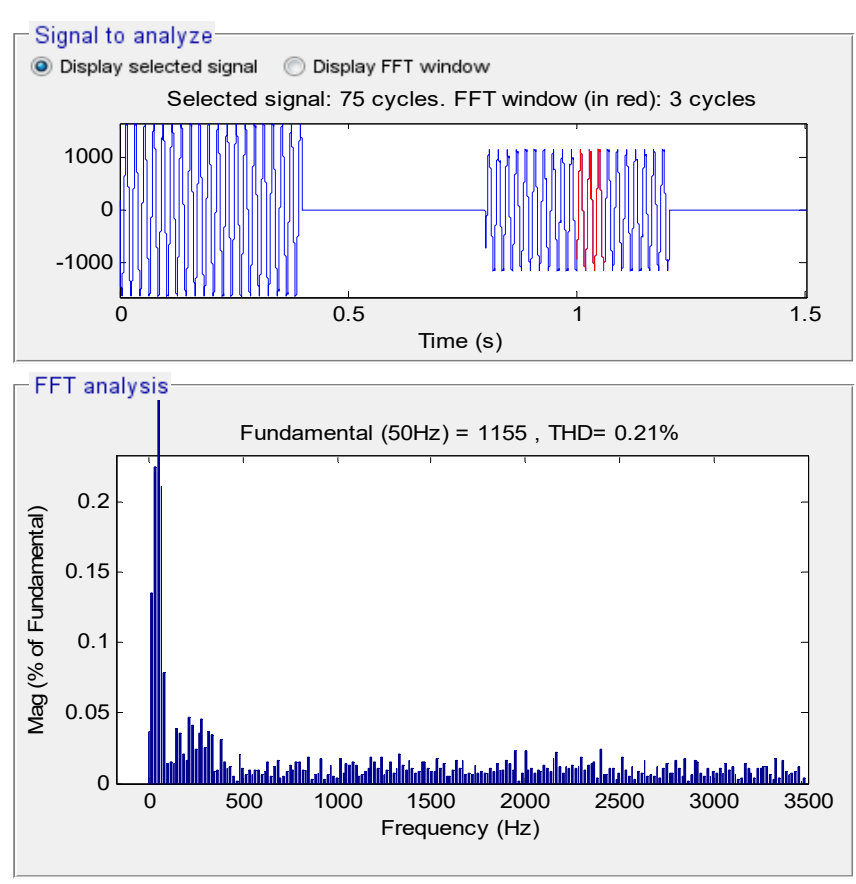

Fig. 11 Spectrum harmonic of stator current (NSOSMC-NSVM).

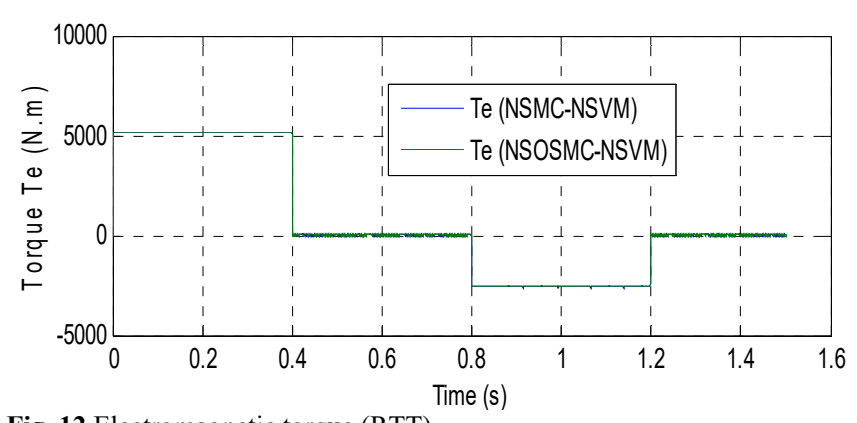

Fig. 12 Electromagnetic torque (RTT).

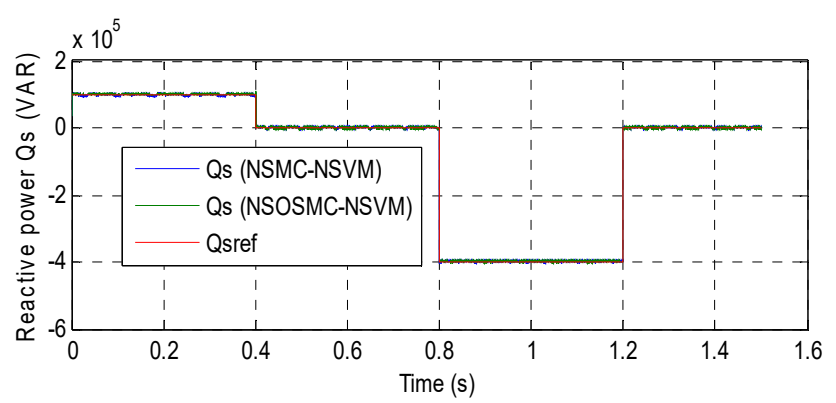

Fig. 13 Reactive power (RTT).

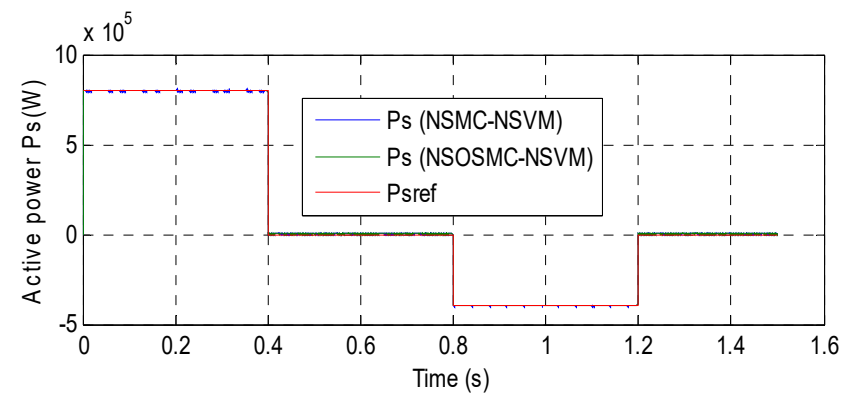

Fig. 14 Active power (RTT).

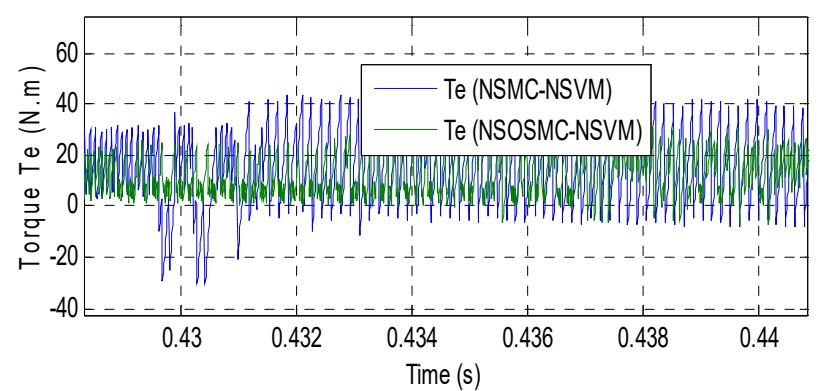

Fig. 15 Zoom in the torque (RTT).

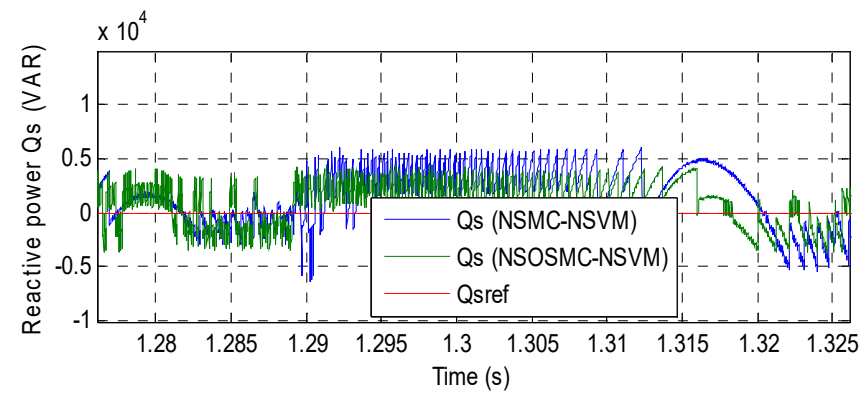

Fig. 16 Zoom in the reactive power (RTT).

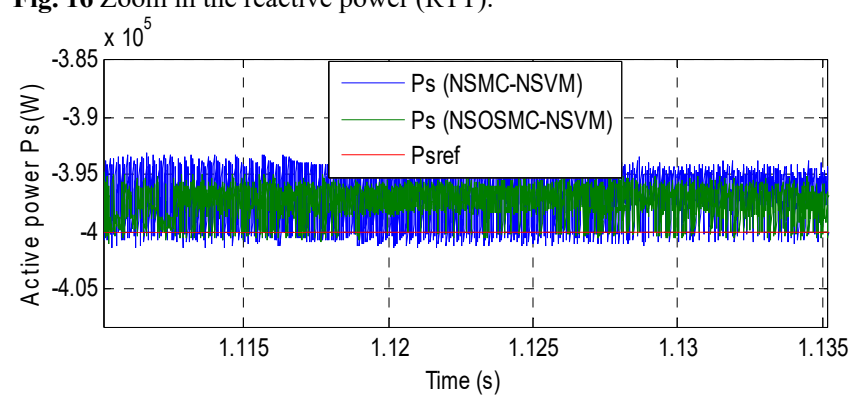

Fig. 17 Zoom in the active power (RTT).

\section{B.Robustness test (RT)}

In this section, the nominal value of the $R_{r}$ and $R_{s}$ is multiplied by 2 , the values of inductances $L_{s}, M$, and $L_{r}$ are multiplied by 0.5 . Simulation results are presented in Figs $18-$ 25. As it's shown by these figures, these variations present an apparent effect on the stator active power, stator reactive power and electromagnetic torque curves and that the effect appears more significant for the NSMC-NSVM control scheme compared to NSOSMC-NSVM (See Figs. 23-25).

The THD value of stator current in the NSOSMC-NSVM control has been minimized significantly (See Figs. 18-19). Table 3 shows the comparative analysis of THD value. Thus it can be concluded that the proposed NSOSMC control with NSVM strategy is more robust than the NSMC--NSVM control scheme.

TABLE 3. COMPARATIVE ANALYSIS OF THD VALUE (RT)

\begin{tabular}{|c|c|c|}
\cline { 2 - 3 } \multicolumn{1}{c|}{} & \multicolumn{2}{c|}{ THD (\%) } \\
\cline { 2 - 3 } \multicolumn{1}{c|}{} & NSMC-NSVM & NSOSMC-NSVM \\
\hline Stator current & 0.54 & $\mathbf{0 . 4 2}$ \\
\hline
\end{tabular}



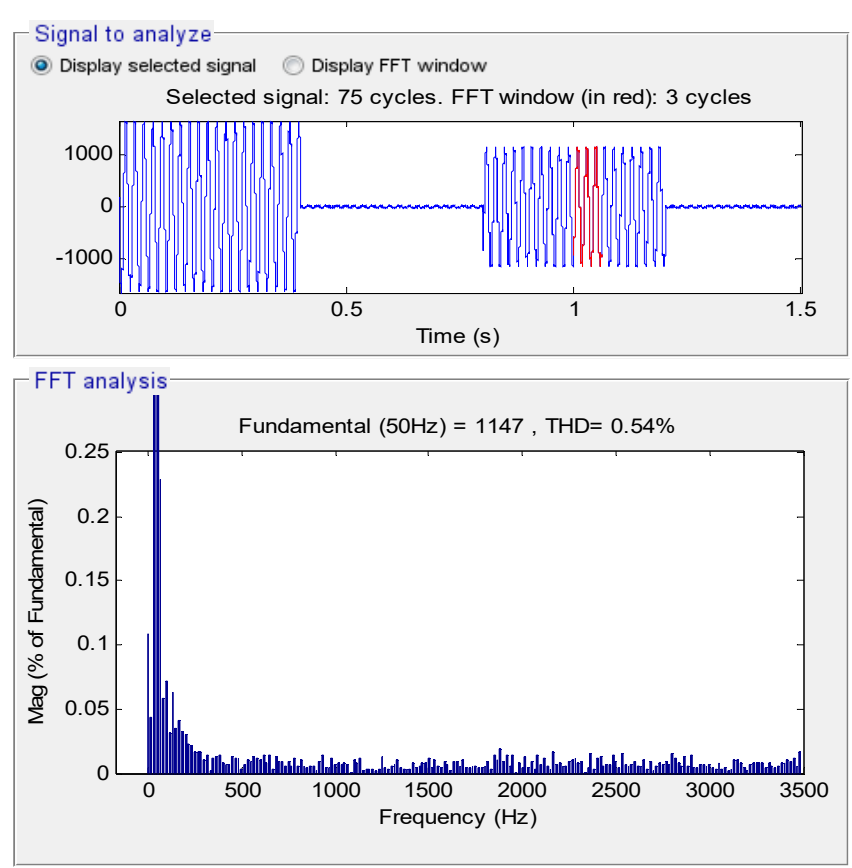

Fig. 18 Spectrum harmonic of stator current (NSMC-NSVM).
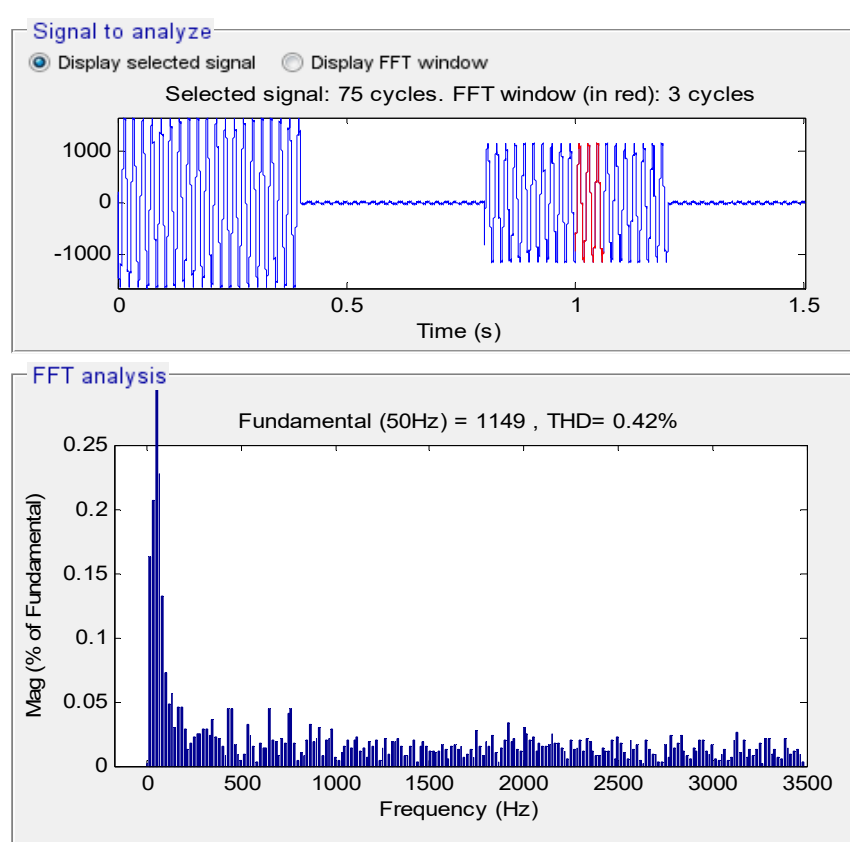

Fig. 19 Spectrum harmonic of stator current (NSOSMC-NSVM).

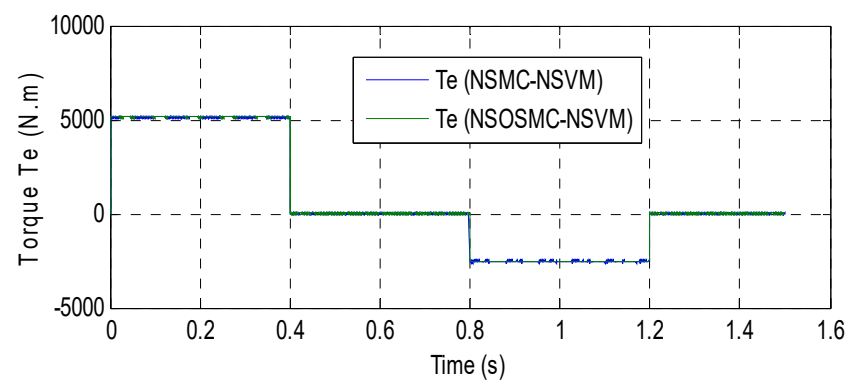

Fig. 20 Electromagnetic torque (RT).

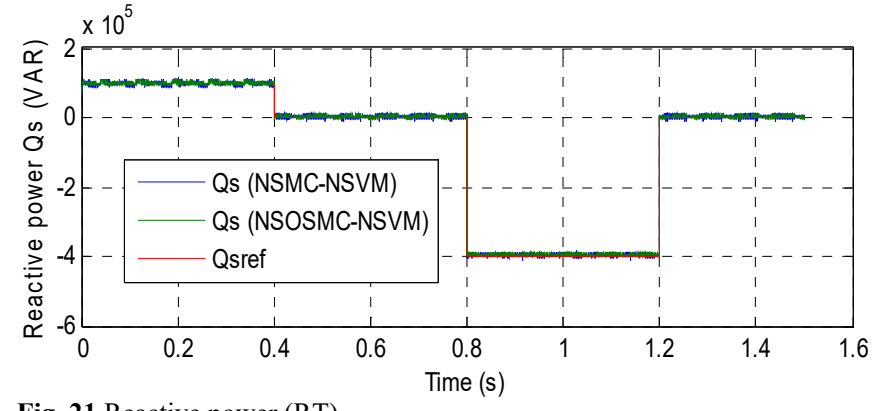

Fig. 21 Reactive power (RT).

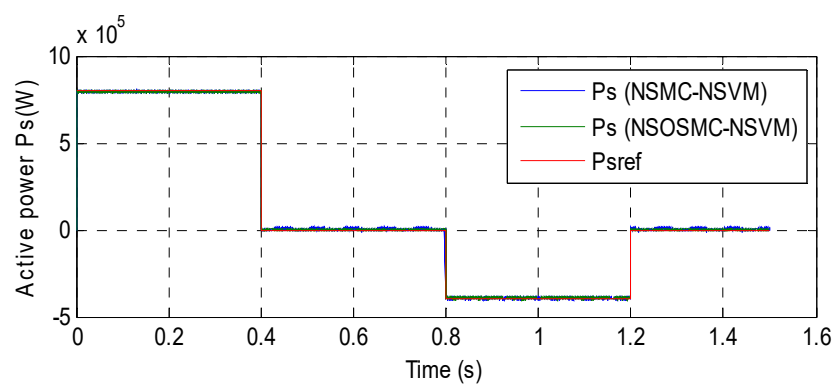

Fig. 22 Active power (RT).

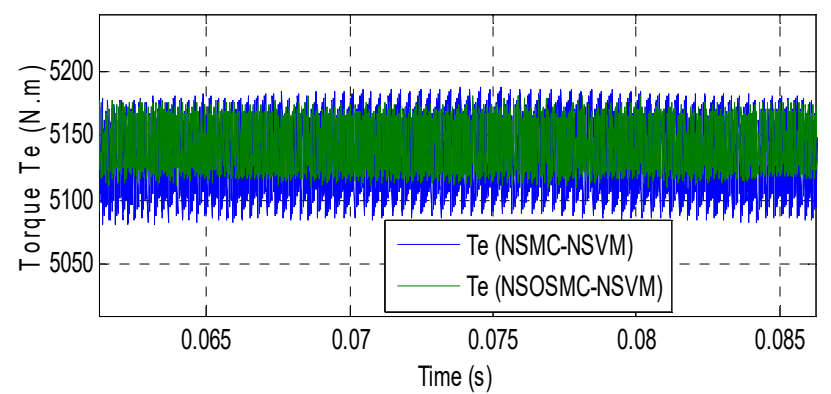

Fig. 23 Zoom in the torque (RT).

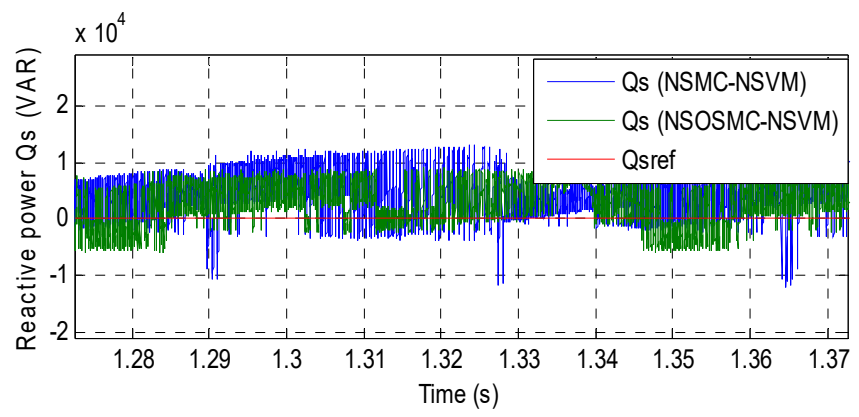

Fig. 24 Zoom in the reactive power (RT).

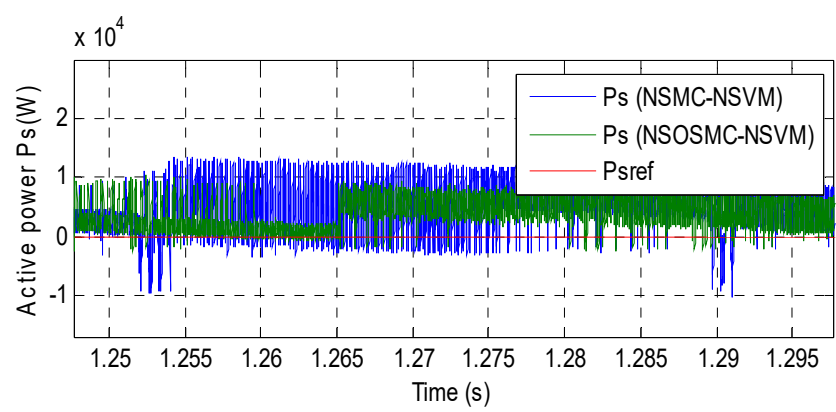

Fig. 25 Zoom in the active power (RT). 


\section{CONCLUSION}

In this paper, a comparative study between the neurosliding mode control with NSVM inverter and neuro-second order sliding mode control with NSVM strategy has been carried out for power control of DFIG. The simulation results obtained for the NSOSMC with NSVM technique illustrate a considerable reduction in reactive power ripple, electromagnetic torque ripple, active power ripple and THD value of stator current compared to the NSMC utilizing twolevel NSVM technique.

\section{APPENDIX}

Table 1. NOMENCLATURE

\begin{tabular}{cc}
\hline Symbol & Significance \\
\hline $\mathrm{S}, \mathrm{R}$ & Rotor and stator indices, \\
$\mathrm{d}, \mathrm{q}$ & Direct and quadrature indices for orthogonal components, \\
$\mathrm{R}_{\mathrm{s}}, \mathrm{R}_{\mathrm{r}}$ & Stator and rotor resistances, \\
$\mathrm{L}_{\mathrm{s}}, \mathrm{L}_{\mathrm{r}}$ & Stator and rotor inductances, \\
$\mathrm{M}$ & Mutual inductances, \\
$\mathrm{p}$ & Number of pairs poles, \\
$\mathrm{J}$ & Inertia \\
$\mathrm{fr}$ & Coefficient of viscous frictions \\
$\mathrm{I}_{\mathrm{dr}}, \mathrm{I}_{\mathrm{qr}}$ & Rotor currents \\
$\mathrm{V}_{\mathrm{dr}}, \mathrm{V}_{\mathrm{qr}}$ & Rotor Voltages \\
$\mathrm{ws}$ & Electrical pulsation of the stator \\
$\mathrm{Vs}$ & Stator voltage \\
\hline
\end{tabular}

\section{REFERENCES}

[1] Z. Boudjema, R. Taleb, Y. Djerriri, A. Yahdou, « A novel direct torque control using second order continuous sliding mode of a doubly fed induction generator for a wind energy conversion system, » Turkish Journal of Electrical Engineering \& Computer Sciences, Vol. 25, Vol. 2, pp. 965-975, 2017.

[2] F. Amrane, A. Chaiba, B. Babas, S. Mekhilef, «Design and implementation of high performance field oriented control for gridconnected doubly fed induction generator via hysteresis rotor current controller, » Rev. Roum. Sci. Techn.-Electrotechn. Et Energ, Vol. 61, No. 4, pp. 319-324, 2016.

[3] Y. Bekakra, D. Ben Attous, «Comparison study between SVM and PWM inverter in sliding mode control of active and reactive power control of a DFIG for variable speed wind energy, » International Journal of Renewable Energy Research, Vol. 2, No. 3, pp. 471-476, 2012.

[4] Z. Boudjema, R. Taleb, A. Yahdou, «A new DTC scheme using second order sliding mode and fuzzy logic of a DFIG for wind turbine system, » International Journal of Advanced Computer Science and Applications, Vol. 7, No. 8, pp. 49-56, 2016.

[5] A. Yahdou, B. Hemici, Z. Boudjema, «Second order sliding mode control of a dual-rotor wind turbine system by employing a matrix converter, » Journal of Electrical Engineering, Vol. 16, No. 4, pp. 1-11, 2016.

[6] H. Benbouhenni, «Comparative study between NSVM and FSVM strategy for a DFIG-based wind turbine system controlled by neurosecond order sliding mode, » Majlesi Journal of Mechatronic Systems, Vol. 7, No. 1, pp. 33-43, 2018.
[7] M. Benkahla, R. Taleb, Z. Boudjema, « Comparative study of robust control strategies for a DFIG-based wind turbine, " International Journal of Advanced Computer Science and Applications, Vol. 7, No. 2, pp. 455-462, 2016.

[8] A. Levant, " Integral high-order sliding modes, » IEEE Trans, Automatic Control, Vol. 52, No. 7, pp. 1278-1282, 2007.

[9] Y. Bekakra, D. B. Attous, « DFIG sliding mode control driven by wind turbine with using a SVM inverter for improve the quality of energy injected into the electrical grid, » ECTI Transactions on Electrical Eng., Electronic, And Communications, Vol. 11, No. 1, pp. 63-75, 2013.

[10] E. G. Shehata, « Sliding mode direct power control of RSC for DFIGs driven by variable speed wind turbines, » Alexandria Engineering Journal, Vol. 54, pp. 1067-1075, 2015.

[11] O. Barambones, J. M. Gonzalez de Durana, « Sliding mode control for power output maximization in a wave energy systems, » Energy Procedia, Vol. 75, pp. 265-270, 2015.

[12] Z. Boudjema, A. Meroufel, A. Amari, « Robust control of a doubly fed induction generator (DFIG) fed by a direct AC-AC converter, » Przegląd Elektrotechniczny, Vol. 11, pp. 213-221, 2012.

[13] S. E. Ardjoun, M. Abid, «Fuzzy sliding mode control applied to a doubly fed induction generator for wind turbines, » Turkish Journal of Electrical Engineering \& Computer Sciences, Vol. 23, Vol. 6, pp. 1673-1686, 2015.

[14] H. Benbouhenni, A. Moussaoui, Z. Boudjema, «Wind energy conversion systems based on a DFIG controlled by neuro-sliding mode control using NSVM and PWM, » International Conference on Electrical Engineering, December 17-18, 2018, El-oued, Algeria.

[15] H. Benbouhenni, « Fuzzy second order sliding mode controller based on three-level fuzzy space vector modulation of a DFIG for wind energy conversion systems, » Majlesi Journal of Mechatronic Systems, Vol. 7, No. 3, 2018.

[16] H. Benbouhenni, B. Zinelaabidine, B. Abdelkader, « Neuro-second order sliding mode control of a DFIG supplied by a two-level NSVM inverter for wind turbine system, " Iranian Journal of Electrical \& Electronic Engineering, Vol.14, No. 3, pp. 362-373, 2018.

[17] H. Benbouhenni, Z. Boudjema, A. Belaidi, « DFIG-based wind turbine system using four-level FSVM strategy, » Majlesi Journal of Energy Management, Vol. 6, No. 3, 2017.

[18] H. Benbouhenni, Z. Boudjema, A. Belaidi, « Direct vector command based on three-level NSVM of a doubly fed induction generator for wind energy conversion, » International Conference on Applied Smart Systems, November 24-25, 2018, Medea, Algeria.

[19] H. Benbouhenni, Z. Boudjema, A. Belaidi, « Using three-level Fuzzy space vector modulation method to improve indirect vector control strategy of a DFIG based wind energy conversion systems, » International Journal Of Smart Grid, Vol.2, No.3 , 2018, pp.155-171.

[20] H. Benbouhenni, Z. Boudjema, A. Belaidi, « DFIG-based wind turbine system using three-level neural space vector modulation technique, » Majlesi Journal of Mechatronic Systems, Vol. 7, No. 2, 2018, pp. 3545.

[21] H. Benbouhenni, Z. Boudjema, A. Belaidi, « DFIG-based WT system using FPWM inverter, » International Journal Of Smart Grid, Vol. 2, No. 3, pp. 142-154, 2018.

[22] H. Benbouhenni, A. Moussaoui, Z. Boudjema, «Wind energy conversion systems based on a DFIG controlled by neuro-sliding mode control using NSVM and PWM, » International Conference on Electrical Engineering, December 17-18, 2018, El-oued, Algeria.

[23] H. Benbouhenni, «Seven-level direct torque control of induction motor based on artificial neural networks with regulation speed using fuzzy PI controller, » Iranian Journal of Electrical and Electronic Engineering, Vol.14, No.1, pp. 85-94, 2018. 